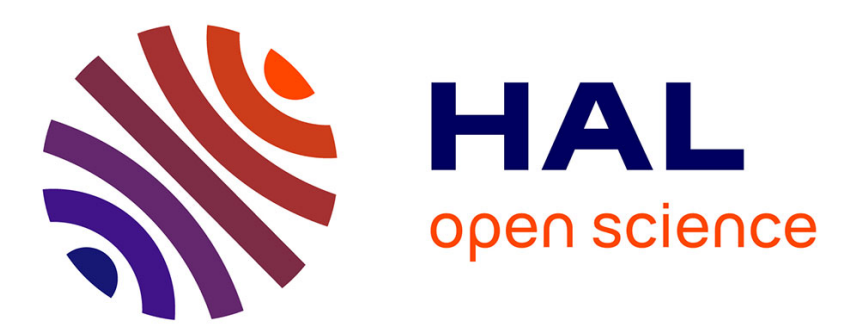

\title{
Shared attention, gaze and pointing gestures I hearing and deaf children
}

Aliyah Morgenstern

\section{To cite this version:}

Aliyah Morgenstern. Shared attention, gaze and pointing gestures I hearing and deaf children. Inbal Arnon, Marisa Casillas, Chigusa Kurumada \& Bruno Estigarribia Language in Interaction. Studies in honor of Eve V. Clark, Benjamins, pp.139-156, 2014, 9789027244017. 10.1075/tilar.12.12mor . halshs-01350595

\section{HAL Id: halshs-01350595 \\ https://shs.hal.science/halshs-01350595}

Submitted on 31 Jul 2016

HAL is a multi-disciplinary open access archive for the deposit and dissemination of scientific research documents, whether they are published or not. The documents may come from teaching and research institutions in France or abroad, or from public or private research centers.
L'archive ouverte pluridisciplinaire HAL, est destinée au dépôt et à la diffusion de documents scientifiques de niveau recherche, publiés ou non, émanant des établissements d'enseignement et de recherche français ou étrangers, des laboratoires publics ou privés.

\section{(ㅇ)(1) $\$$}

Distributed under a Creative Commons Attribution - NonCommercial - NoDerivatives $\mid 4.0$ 
Morgenstern, A. (2014). Shared attention, gaze and pointing gestures I hearing and deaf children in Inbal Arnon, Marisa Casillas, Chigusa Kurumada \& Bruno Estigarribia (Eds.), Language in Interaction. Studies in honor of Eve V. Clark. Amsterdam/Philadelphia: John Benjamins.139-156.

Shared attention, gaze and pointing gestures

in hearing and deaf children

Aliyah Morgenstern

Sorbonne Nouvelle University

\section{Abstract}

This chapter illustrates the richness of pointing and gazing as integral elements of spontaneous oral interactions both in signing and speaking mother-child dyads. These attention-sharing behaviors help infants to interpret their caregivers' productions. The children will then use them themselves as first communication tools. They also have a particular function for deaf signing children since they are fully integrated into the formal linguistic system of sign language. A comparison between the use of pointing and gaze in the longitudinal data of one deaf signing and one deaf speaking little girl from eight months to two shows that the deaf child uses gaze and pointing more frequently and with more diversified functions than the hearing child. She develops an expertise at using the visual modality while the hearing child combines visual and auditory means.

Eve Clark has always been at the heart of my scientific life. I cannot remember how and when I met her in person. She seems to have always been there for me, first as a conversational partner in my imaginary dialogues with her as I kept reading her books and her papers, or wrote my own; more recently, as a god-mother, a mentor, a friend, who regularly comes to Paris and with whom I share intense conversations, good meals and 
Morgenstern, A. (2014). Shared attention, gaze and pointing gestures I hearing and deaf children in Inbal Arnon, Marisa Casillas, Chigusa Kurumada \& Bruno Estigarribia (Eds.), Language in Interaction. Studies in honor of Eve V. Clark. Amsterdam/Philadelphia: John Benjamins.139-156.

great affection. She is constantly telling me to stop doing so much, to sit down and WRITE. So here I am, writing for you Eve, a brief respite.

Even though children have innate biological and cognitive capacities, they need to learn linguistic conventions and formal patterns from the language in their environment. They gradually become fully bloomed interacting speakers building on such cognitive and social skills as the ability to follow the other's gaze, to draw and maintain their attention, to read others' intentions, to make analogies, to categorize and to symbolize.

Eve Clark has made innumerable in-depth scientific contributions to show that nativist views of language development might not be adequate, and that a complete account of language development must carefully consider children's social experience and in particular adult-child interactions. She has patiently collected and neatly assembled data to show again and again, in the most elegant manner, the wonderful "richness of the stimulus". This rich input includes gaze and pointing, and I shall try to illustrate in this chapter their importance as integral elements of language, both in signing and speaking children. Gestures, verbal productions, signs, gaze, facial expressions, postures, are all part of our socially learned, inter-subjective communicative system. Human beings, with all their representational skills, combine modalities in order to share meaning, to refer to present and absent entities and events, to express their projects, their desires and their inner feelings. As McNeil pointed out, we might need to "broaden our concept of language" (1992: 2). Thanks to combinations of experimental and ecological studies, to video recordings, to a variety of specialized software, international databases, theoretical approaches that include multimodality and multiple levels of analyses, rich collaborations among experts of several scientific 
Morgenstern, A. (2014). Shared attention, gaze and pointing gestures I hearing and deaf children in Inbal Arnon, Marisa Casillas, Chigusa Kurumada \& Bruno Estigarribia (Eds.), Language in Interaction. Studies in honor of Eve V. Clark. Amsterdam/Philadelphia: John Benjamins.139-156.

fields related to language development, we now have the tools that help us create new methods to do so.

\section{Introduction}

Social interaction in infancy is dependent on the interplay between infants' affects, their neural learning processes, their perceptual and motor skills and the structure of their social and affective environment (Cole \& Cole 1996). Social information helps infants decipher the meaning of others' language acts (Tomasello 1999). Their drive to attend to the same objects helps infants enter the language community.

Infants' capacity for attention sharing therefore plays a crucial role in their communication with older children and adults (Brazelton, Koslowki, \& Main 1974; Bruner 1983; Baldwin 1993; Tomasello 1999). The notion of shared or joint attention ${ }^{1}$ is used for a whole range of skills that include gaze following, request gestures and postures, and especially pointing. By 9-12 months, even though there are great individual differences in their rhythm of development, most infants follow adults' gaze and pointing gestures and learn to discriminate what is important for them in their environment, based on the attention shown and the feedback given by more expert caregivers.

It is the interaction and complementarity between basic perceptual, cognitive and affective processes that seem to trigger and guide the emergence of shared attention, which will then lead the child into symbolic communication (Deak \& Triesch 2006).

\footnotetext{
${ }^{1}$ Some authors have different definitions of these two notions but I will use them indifferently.
} 
Morgenstern, A. (2014). Shared attention, gaze and pointing gestures I hearing and deaf children in Inbal Arnon, Marisa Casillas, Chigusa Kurumada \& Bruno Estigarribia (Eds.), Language in Interaction. Studies in honor of Eve V. Clark. Amsterdam/Philadelphia: John Benjamins.139-156.

Adults and older children constantly recruit infants' attention. Attention-sharing behaviors used by adults such as gaze and pointing gestures first help infants interpret their caregivers' productions. But the children will then use these attention-sharing processes themselves as first communication tools with reinforcement from adults. Children can thus request the adults' attention and monitor it skillfully as they grow up: "gaze and gesture are the early means through which the child can take part in conversation and maintain participation across sequences of talk" (Filipi 2009: 2).

\subsection{Gaze in hearing and deaf children}

However important gaze is both in the input and in children's communicative behavior, from their very first weeks into the world, all sorts of sounds and visual cues can compete for infants' attention in their ecological environment. Even in experimental studies, adults use verbal cues more often than gesture or gaze as attention getters (before the children look at the objects), especially with young children under 1;6, (Estigarribia and Clark 2007). They will then rely on the children's gaze to know if they are attending.

Object manipulation is also of high importance during the first year (You, Deak \& Jasso 2005). According to Deak, Jasso, Krasno \& Triesch (2006), infants almost never follow caregivers' gaze shifts unless the adult also manipulates the object or points. In their study in quasi-naturalistic conditions, infants followed mostly combinations of manual actions and gaze shifts. During the play sessions, adults then complemented most of their speech with gestures and constantly referred verbally to the toys they were manipulating. 
Morgenstern, A. (2014). Shared attention, gaze and pointing gestures I hearing and deaf children in Inbal Arnon, Marisa Casillas, Chigusa Kurumada \& Bruno Estigarribia (Eds.), Language in Interaction. Studies in honor of Eve V. Clark. Amsterdam/Philadelphia: John Benjamins.139-156.

Hearing children can therefore learn visual skills very early on, but rely on a combination of semiotic cues used by their adult interlocutors to attract and maintain their attention. They also use a combination of multimodal means themselves to imitate those behaviors. What then is the situation of deaf children who cannot rely on the auditory modality?

Like all children, deaf children learn about the world thanks to shared attention with their communication partners. But they enter language only through visual attention $^{2}$. While hearing children can be looking around them and listening to their caregivers at the same time, deaf children explore their environment AND perceive all their language input thanks to the visual mode. How does the use of one single modality impact their joint attention skills?

Limousin (2011) has shown in a longitudinal study of a French deaf little girl's linguistic development, her French deaf signing parents' incredible skills at adjusting to their daughter's visual development as she grew up. They constantly used different means to attract and maintain her attention, tapping her lightly, waving their hands towards her, or tapping their foot on the floor to establish eye contact. They could also notice when her concentration was weaker and she needed some respite. They bent down to sign right in her visual field, as she was much smaller than them. They sometimes signed directly in front of her eyes. As she grew up, they trusted her more and started signing with fewer repetitions, more quickly, with smaller movements - thus less saliently (i.e. their prosody became less emphatic, as in hearing Child Directed Speech) and without adopting special positions. All these specific strategies are referred

\footnotetext{
2 I don't want to dismiss the other senses, Touch and in some degree Taste (in the shape of mouthing, one of the babies' ways of exploring the world), that certainly play an important role in child development, and contribute to language development even more in the case of blind infants, but I will not discuss them in this study.
} 
Morgenstern, A. (2014). Shared attention, gaze and pointing gestures I hearing and deaf children in Inbal Arnon, Marisa Casillas, Chigusa Kurumada \& Bruno Estigarribia (Eds.), Language in Interaction. Studies in honor of Eve V. Clark. Amsterdam/Philadelphia: John Benjamins.139-156.

to as "Infant directed sign" (Masataka 1996, Mayberry \& Squires 2006). Just as Child Directed Speech scaffolds hearing children's use of oral language, Child Directed Sign helps deaf children acquire the same conversational skills but adapted to a visual language. The facilitative strategies enable deaf children to acquire sign language, by attracting and holding their attention. When deaf children do not benefit from those strategies (and only a minority of deaf children have deaf signing parents), their linguistic, emotional and social development can be highly hampered (Courtin 2000; Meristo et al. in press).

Deaf children who benefit from Child Directed Sign develop skills that enable them to engage in joint attention from a very young age. Two year olds constantly shift their gaze back and forth and therefore connect the speech addressed to them to the objects referred to. Such precocious meaningful gaze shifting has not been found in hearing children the same age. They reflect specific skills developed from perceiving all of language visually.

Deaf children therefore learn to control their own eye gaze in order to alternate attention between signers and objects. If they don't learn those skills quickly enough, they don't "see" enough language, communication is "incomplete" and they do not fully benefit from their input. Hearing children can stop concentrating, get engrossed in their activity, but they still hear verbal productions.

Eye-gaze then becomes an integral part of sign language itself since it is "grammaticalized" and serves different linguistic functions. Eye gaze is for example what enables signers to distinguish between narrative - gaze is not on the interlocutor - and dialogue - gaze is on the interlocutor (Cuxac 2000). It also plays a syntactic role to mark pronominal reference (differentiating second and third person, either complementing or 
Morgenstern, A. (2014). Shared attention, gaze and pointing gestures I hearing and deaf children in Inbal Arnon, Marisa Casillas, Chigusa Kurumada \& Bruno Estigarribia (Eds.), Language in Interaction. Studies in honor of Eve V. Clark. Amsterdam/Philadelphia: John Benjamins.139-156.

replacing pointing gestures). Eye gaze is therefore an important element of sign productions and must be finely controlled and monitored by children for them to become expert signers. They can only benefit from early focus from their caregivers on the development of the complex abilities necessary to master visual interaction.

\subsection{Pointing in hearing and deaf children}

Pointing, especially with an outstretched and aligned arm, hand and finger (or other parts of the body) is a very natural and salient way to direct another's attention to a new object (Butterworth \& Itakura 2000). Caregivers and infants produce pointing gestures to direct each other's attention (Bates, Camaioni \& Volterra 1975). Pointing is used by adults once they move away from things that are in "the immediate vicinity of the infant" and which they can handle, show them and hand to them. Thanks to very fine motor adjustments between hand and eye, the children will then pick the things up themselves, handle then, show them, give them to the adult (Clark 1978: 93). Children then also take up those pointing gestures directed at them, and will reciprocate by showing, commenting or requesting objects that are out of reach with the same means. Of course pointing gestures are rare by comparison to gaze shifting, but they are more salient for infants because of the movement they involve. They also imply more 'effort' and children may think the target is even more interesting when pointing is used. Ninemonth-old children follow gaze much more reliably when it is accompanied by a pointing gesture (Flom, Deak, Phill \& Pick 2003).

Pointing gestures play an important role in the language acquisition process. They are grounded in joint attention, they trigger interaction, and they may also facilitate 
Morgenstern, A. (2014). Shared attention, gaze and pointing gestures I hearing and deaf children in Inbal Arnon, Marisa Casillas, Chigusa Kurumada \& Bruno Estigarribia (Eds.), Language in Interaction. Studies in honor of Eve V. Clark. Amsterdam/Philadelphia: John Benjamins.139-156.

children's entry into word combination and syntax (Iverson and Goldin-Meadow 2005; Kelly 2011). Numerous studies have tackled this issue in the development of spoken language. The "founding fathers" of the study of child development and language had great intuitions about the importance of gestures and their relation to language. In his notes on his son's development, Darwin (1877) stresses the importance of observing the transition from uncontrolled body movements to intentional gestures. Stern (1924) considers pointing in particular as a precursor of intentional marking. For Werner and Kaplan (1963), pointing represents children's ability to discriminate between external objects and their own person. Communicational pointing then becomes the basis for referential behavior and reciprocity established in common activities between children and their parents (Bruner 1975). As Tomasello et al. underline, "pointing may thus represent a key transition, both phylogenetically and ontogenetically, from nonlinguistic to linguistic forms of human communication." (2007: 720).

The issue of continuity between gesture and language is quite challenging in the case of sign language, since pointing gestures are fully integrated in the linguistic system (Hoiting \& Slobin 2007), just as gaze is grammaticalized (as explained above). The analysis of pointing in sign language acquisition is a unique occasion to observe the possible continuity or discontinuity between gesture and sign in the Saussurian sense.

When children first produce pointing gestures both in speaking or signing environments, they designate a place, an object, a person or sometimes an event. But for the child who is surrounded by sign language, those pointing gestures are progressively incorporated into her formal linguistic system and used for demonstrative and personal reference among other functions in combination with gaze. 
Morgenstern, A. (2014). Shared attention, gaze and pointing gestures I hearing and deaf children in Inbal Arnon, Marisa Casillas, Chigusa Kurumada \& Bruno Estigarribia (Eds.), Language in Interaction. Studies in honor of Eve V. Clark. Amsterdam/Philadelphia: John Benjamins.139-156.

Continuity between pointing gestures and language is questioned by Bellugi \& Klima (1982) and Petitto (1986), based on their observations of a time-line discontinuity in the production of pointing gestures. The deaf signing children they observed ceased using points and when they started using them again, there were instances of pronominal inversions. According to these authors, children's pre-linguistic gestures are different from signs despite the same hand-shape and may correspond to two distinct categories of pointing gestures: some indexical and some symbolic (Tomasello 2003). While discontinuity between pointing gestures and points used as personal pronouns was thus illustrated in the acquisition of American Sign Language, the same phenomenon was not confirmed in Italian Sign Language with longitudinal data (Pizzutto \& Capobianco 2005), nor in the longitudinal recordings of deaf children using French Sign Language (Morgenstern 1997; Limousin 2011) which showed no interruption of pointing toward persons and no pronominal reversal. These observations were not confirmed either in other longitudinal studies of children using ASL.

The problem is that the pointing signs used for personal pronouns and demonstratives, do not look very different from the pointing pre-linguistic or co-verbal gestures used by hearing children. Because "points are considered linguistic in the adult system, it is tempting to consider the child's points as linguistic" (Schick 2003: 221). How are we to decide whether the nature of pointing is linguistic or "nonlinguistic"/"pre-linguistic"? Most sign language researchers assume that these pointing signs are pronouns, but this assumption is challenged by Evans and Levinson (2009) and Cormier (2010). Pointing signs do not look different on the surface from pointing in non-signers (Kendon 2004; Kita 2003). In both cases, points index locations of objects, 
Morgenstern, A. (2014). Shared attention, gaze and pointing gestures I hearing and deaf children in Inbal Arnon, Marisa Casillas, Chigusa Kurumada \& Bruno Estigarribia (Eds.), Language in Interaction. Studies in honor of Eve V. Clark. Amsterdam/Philadelphia: John Benjamins.139-156.

persons, events in the deictic space. Some studies, however, have focused on specific features of pointing in deaf children and on their ability to use different forms and types of pointing for different functions (with the combinatorial dimensions of finger, wrist and arm configuration, movement, intensity and speed). Not only do deaf children use an impressive amount of pointing gestures from very early on, but the functions of these points are "integrated into the process of conventionalization of gesture and control of the signing space” (Hoiting 2009: 84).

In order to tackle the differences between French and French Sign language, I will compare the role of shared attention, gaze and pointing gestures in the interactions between two little girls and their parents in their natural environment. We will not try to categorize points as being either "linguistic" or "gestural". Symbolic gestures are part of our broad, integrative view of language as a multimodal interactive system and we will focus on the development of pointing within the communication systems that children develop, be they spoken or signed. Two studies conducted in the framework of the CoLaJE project financed by the French National Agency (Morgenstern et.al 2010) are presented here in order to make an attempt at establishing comparisons between two longitudinal follow-ups in two different situations. The researchers ${ }^{3}$ coded the data together in order to conduct comparable analyses ${ }^{4}{ }^{5}$

\footnotetext{
${ }^{3}$ The team on pointing gestures included at various stages of the project Emmanuelle Mathiot, Fanny Limousin, Marion Blondel, Dominique Boutet and myself, the team on personal reference included Stéphanie Caët, Fanny Limousin, Marion Blondel and myself.

${ }^{4}$ The coding of Charlotte's data was conducted by Fanny Limousin with the help of Stéphanie Caët and discussed during regular working sessions with Aliyah Morgenstern. The coding for Madeleine's sessions was done by Marie Collombel-Leroy, Emmanuelle Mathiot and Aliyah Morgenstern.

${ }^{5}$ Despite the use of video data, rich coding systems with video and transcription alignment using CLAN and ELAN, some specific analyses could not be conducted. We were not able to study the parents' gaze for instance: the camera operator did not always film the adults with enough attention when the child was producing gestures, words or signs.
} 
Morgenstern, A. (2014). Shared attention, gaze and pointing gestures I hearing and deaf children in Inbal Arnon, Marisa Casillas, Chigusa Kurumada \& Bruno Estigarribia (Eds.), Language in Interaction. Studies in honor of Eve V. Clark. Amsterdam/Philadelphia: John Benjamins.139-156.

\section{Shared attention, gaze and pointing in two longitudinal follow-ups}

\subsection{The data}

Madeleine ${ }^{6}$ is a French monolingual hearing little girl with two hearing monolingual parents, an older sister and a younger brother. She lives in Paris in an upper-middle class family. She was taken care of by a nanny until she entered kindergarten. Martine Sekali filmed her for one hour nearly once a month from the age of ten months to the age of seven (Morgenstern \& Parisse 2012; Sekali 2012).

Charlotte is a deaf little girl raised by deaf middle-class parents who both use French Sign Language. She is their first child. She was filmed for one hour once a month from the age of seven months to three. Charlotte lives in Paris and attended a day-care center at the time with one deaf educator. She was filmed exclusively by Fanny Limousin, a deaf signing junior researcher ${ }^{7}$.

The two little girls were quite precocious in their linguistic development and could be considered as quite comparable in the two modalities used. Their data has been analyzed for various studies focusing on prosody and morpho-syntax which gives us more insight on their linguistic development (Morgenstern \& Sekali 2009; Morgenstern

\footnotetext{
${ }^{6}$ The data is part of the Paris corpus financed by the French Research Agency (ANR) in the framework of the Léonard Project directed by Aliyah Morgenstern and is available on CHILDES (http://childes.psy.cmu.edu).

${ }^{7}$ See Limousin 2011 for a detailed account of Charlotte's data.
} 
Morgenstern, A. (2014). Shared attention, gaze and pointing gestures I hearing and deaf children in Inbal Arnon, Marisa Casillas, Chigusa Kurumada \& Bruno Estigarribia (Eds.), Language in Interaction. Studies in honor of Eve V. Clark. Amsterdam/Philadelphia: John Benjamins.139-156.

2009; Limousin 2011; Morgenstern \& Parisse 2012; Sekali 2012). For this study, we used the data up to two years old.

\subsection{Comparing children's acquisition of LSF and French}

We can observe the important differences between the two languages, due to the modalities used, in detail in the interactions between Madeleine and Charlotte.

One of the major differences between the mother/ child dyads we have studied lies in the use of GAZE. The eyes of Charlotte's mother are her essential link with her child and enable her to check how safe and well she is at all times. Her visual field is therefore wider than that of the hearing mother. However, when Charlotte wants to draw her mother's attention while she points, she makes intense movements using her head, legs and bust. She can also repeat the pointing gesture. Another of her strategies is to become totally still and gaze fixedly at her mother. Therefore the amplification or absence of movement is a marked form as opposed to normal gestures. Those strategies demonstrate how much Charlotte is aware of her mother's attention (or lack of it) and how she is able to manage and monitor gaze quite skillfully.

Another difference is that in oral language, sound, gesture and gaze are all extremely important in early communication, whereas in Sign language, gesture and gaze are predominant. A child exposed to sign language might therefore be even more sensitive to gesture, and deaf adults are going to interpret (and over-interpret) their children's first gestures much earlier, just like hearing adults might do with babbling.

Because gaze and gestures are so central to communication, the articulation between daily activities and language is totally different. In the hearing dyad, the mother 
Morgenstern, A. (2014). Shared attention, gaze and pointing gestures I hearing and deaf children in Inbal Arnon, Marisa Casillas, Chigusa Kurumada \& Bruno Estigarribia (Eds.), Language in Interaction. Studies in honor of Eve V. Clark. Amsterdam/Philadelphia: John Benjamins.139-156.

is often doing other things while she talks to her child. In the deaf dyad, it is more difficult to communicate in sign language while you do a manual activity: you cannot sign with both your hands and your whole body, as required for Child Directed Sign, and efficiently cook, change a diaper, clean, sort papers at the same time. The interactional mode is therefore quite specific. The EYES replace the EARS and the mother is constantly «visually listening » to her child. The language moments are intense; both participants are focused on the other. Language is mostly a mono-activity. Of course, when children grow up, their interlocutors can rely on their child's experience in sign and use one hand or smaller movements to sign with them. The children themselves will acquire the ability to act and sign much more simultaneously.

There is another main difference between vocal and sign languages that seems to be an advantage for the explicit role of adults in the child's learning process: it is easier for a parent to modify the child's manual mode by acting on their hands, shaping, modeling them, than it is to rectify the oral mode. You cannot act on a child's vocal tract.

However, there are also apparent disadvantages in the use of visual languages: when the child is not focusing on interactions going on around her, she is cut off from non-addressed speech. We have numerous examples of Charlotte's mother signing to the observer out of Charlotte's visual field (behind her for example). In those cases, which are quite frequent, Charlotte has no access to this non-addressed speech whereas Madeleine constantly hears the adults speaking to each other and therefore has very frequent access to non-addressed speech.

\subsection{Talkativeness in the two children}


Morgenstern, A. (2014). Shared attention, gaze and pointing gestures I hearing and deaf children in Inbal Arnon, Marisa Casillas, Chigusa Kurumada \& Bruno Estigarribia (Eds.), Language in Interaction. Studies in honor of Eve V. Clark. Amsterdam/Philadelphia: John Benjamins.139-156.

In order to measure whether these differences have an impact on the children's density of Speech/Sign, we made a quantitative analysis of turn taking in the signing dyad and the speaking dyad. This showed that the number of turns exchanged in the hearing dyad per hour is twice the number of turns exchanged in the signing dyad in two different videos (table 1).

Table 1. Number of turns produced by the children in an hour at 1;7 and 2;0 years ${ }^{8}$.

\begin{tabular}{lcc}
\hline & $1 ; 7$ & $2 ; 0$ \\
\hline Charlotte & 134 & 152 \\
Madeleine & 285 & 395 \\
\hline
\end{tabular}

The difference in the number of turns between Charlotte and Madeleine at 1;07 and 2;0 remains stable. The increase is proportionally similar for the two girls $\left(\chi^{2}(1)=1.805, p=0.18\right)$.

There seems to be an important impact of the different conversational styles and the constraints linked to the use of a visual language. With those differences in mind, we will now turn to the two little girls' use of pointing.

\section{Pointing and gaze in Madeleine and Charlotte's data}

\subsection{Quantitative use of pointing gestures in Madeleine and Charlotte's data}

\footnotetext{
${ }^{8}$ Taken from Morgenstern et al. (2010).
} 
Morgenstern, A. (2014). Shared attention, gaze and pointing gestures I hearing and deaf children in Inbal Arnon, Marisa Casillas, Chigusa Kurumada \& Bruno Estigarribia (Eds.), Language in Interaction. Studies in honor of Eve V. Clark. Amsterdam/Philadelphia: John Benjamins.139-156.

One of our hypotheses was that Charlotte would produce more pointing gestures than Madeleine because of the nature of their input (French and gestures in Madeleine's case, Sign Language and gestures in Charlotte's case). In order to draw a comparison between the two girls, we extracted the total number of pointing gestures per one-hour session in our data (Figure 1).

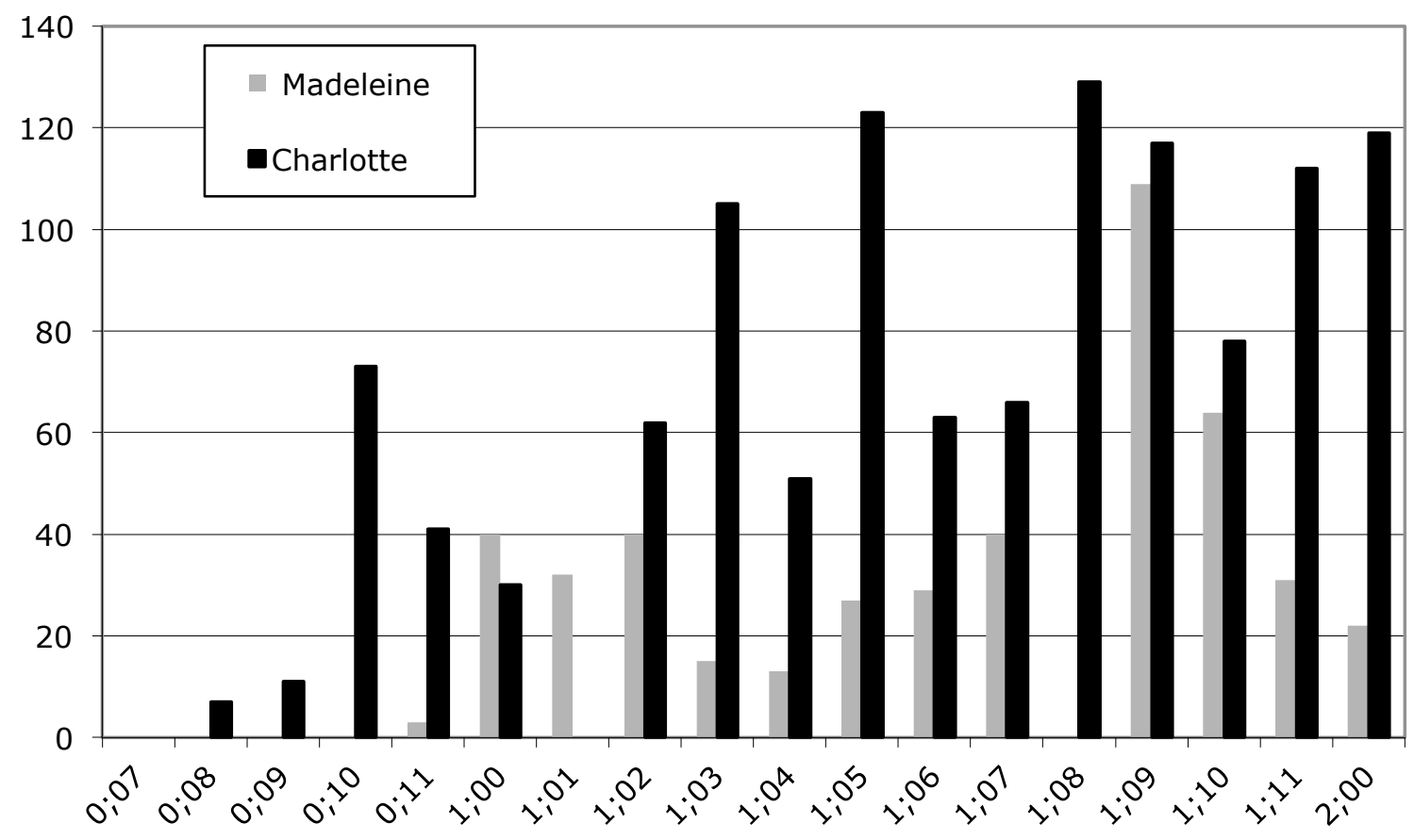

Figure 1. Number of pointing gestures produced in an hour for the two children according to age.

For each child, the number of pointing gestures is very variable from one session to another according to the situations. Nevertheless, Charlotte produces pointing gestures three months earlier and more frequently in the 18 recordings (1187 in total) than Madeleine (465). The sessions when Madeleine uses a lot of pointing gestures $(1 ; 09$ 
Morgenstern, A. (2014). Shared attention, gaze and pointing gestures I hearing and deaf children in Inbal Arnon, Marisa Casillas, Chigusa Kurumada \& Bruno Estigarribia (Eds.), Language in Interaction. Studies in honor of Eve V. Clark. Amsterdam/Philadelphia: John Benjamins.139-156.

and $1 ; 10$ ) contain a lot of book-reading situations. The frequency of pointing gestures Charlotte produces increases irregularly but gradually between 7 months and 2 years.

Since Charlotte's "communicative" turns are two times less frequent than Madeleine's, this high number of occurrences of pointing gestures in the same sessions might be considered surprising. The quantity of pointing gestures per turn is four to five times denser in Charlotte's data. But this could be linked to the high frequency of points and their grammaticalization in the input language, French Sign Language. In Charlotte's data, the adults use an average of 200 points per hour session, whereas in Madeleine's session, there is an average of 40 points per hour session. The overall number of points per hour actually decreases in her input when Madeleine gets older and stays stable in Charlotte's input.

\subsection{Use of gaze during pointing events in Charlotte and Madeleine's data}

Here, we do not analyze the gestures on their own, but consider the combination of pointing gestures and all the complementing elements (gaze, vocal productions and words/signs) as pointing events (Leroy et al. 2009)9 .

Gaze towards the adult is generally considered an essential sign of the child's intention to communicate. The name given in the literature for this phenomenon is "visual checking". In an experimental situation, Franco and Butterworth (1996) have observed that the association between the children's pointing gestures and gaze

\footnotetext{
${ }^{9}$ The basic unit of pointing event is the pointing gesture. They always include gaze on the target or the adult. They often include synchronous vocal productions, words or other gestures/signs (sometimes produced with the other hand or even combined with the pointing gesture when the child is old enough to produce those complex combinations).
} 
Morgenstern, A. (2014). Shared attention, gaze and pointing gestures I hearing and deaf children in Inbal Arnon, Marisa Casillas, Chigusa Kurumada \& Bruno Estigarribia (Eds.), Language in Interaction. Studies in honor of Eve V. Clark. Amsterdam/Philadelphia: John Benjamins.139-156.

towards the adult develops with age. At 10 months, there is pointing with gaze on the object, then at 12 months, the child points then gazes at the adult, finally at 15 months, the child gazes at the adult and then points. But in their natural environment, there are situations when children do not look at the adults because their attention is already focused, for example when the child and the mother are looking at a book together. When Madeleine is $1 ; 01$, she and her mother point one after the other at different pictures in a book, but the child does not gaze at her mother at all and even has her back to her.

We also noticed that when Madeleine points without looking at her mother, she very often makes vocal productions, and even associates the pointing gesture to a recognizable two syllable word [œga] that seems to be a reproduction of her mother's very frequent use of "regarde!" (look) when she points. The combination of the auditory and the visual modality might not require the added use of visual checking as often. Charlotte does not use vocal productions with her points, at least not intentionally. Only one modality is involved. Since the two little girls do not have the same attention getting tools at their disposal, will their use of gaze during pointing events be the same?

To answer that, we coded all the gazes occurring with pointing events in our longitudinal data from the beginning of the data to 1;07 (for technical reasons, we couldn't code the use of gaze in certain sessions after 1;07, see Figures 2 and 3). 
Morgenstern, A. (2014). Shared attention, gaze and pointing gestures I hearing and deaf children in Inbal Arnon, Marisa Casillas, Chigusa Kurumada \& Bruno Estigarribia (Eds.), Language in Interaction. Studies in honor of Eve V. Clark. Amsterdam/Philadelphia: John Benjamins.139-156.

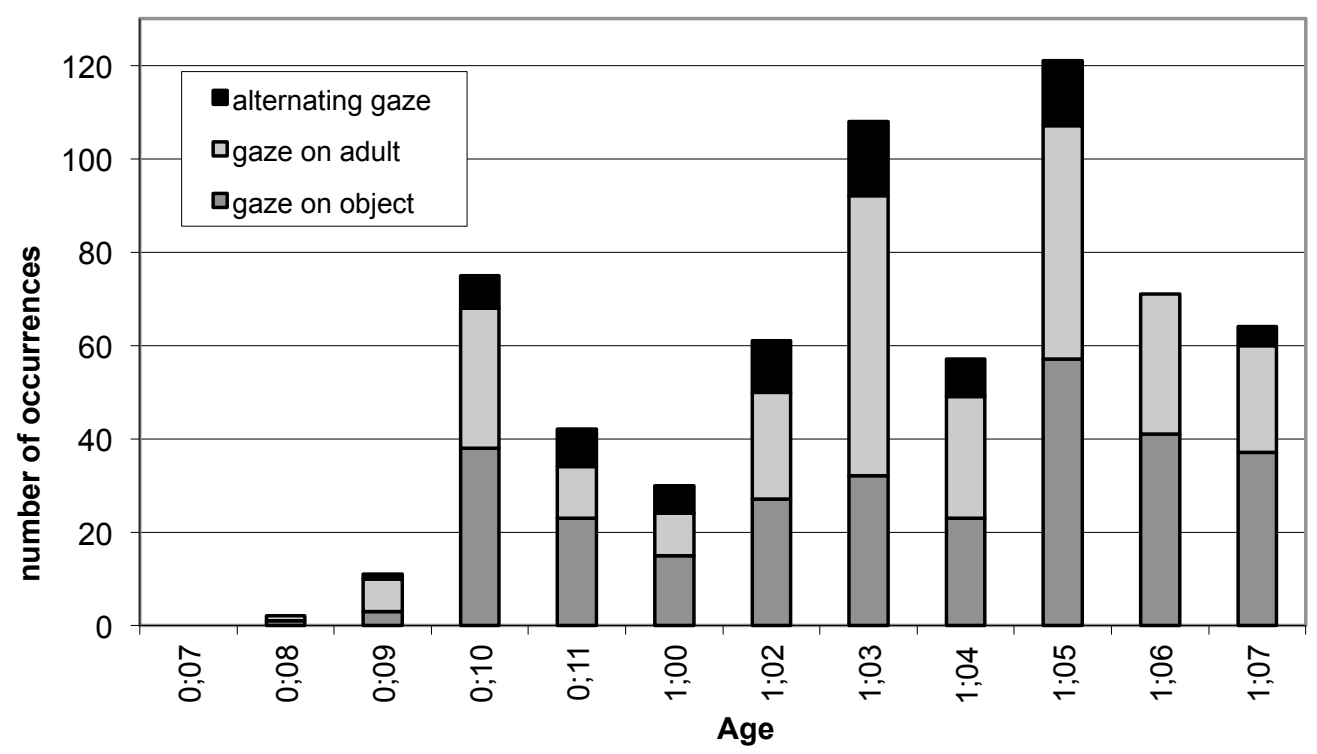

Figure 2. Number of occurrences of gaze on object, gaze on adult and alternating gaze during Charlotte's pointing events.

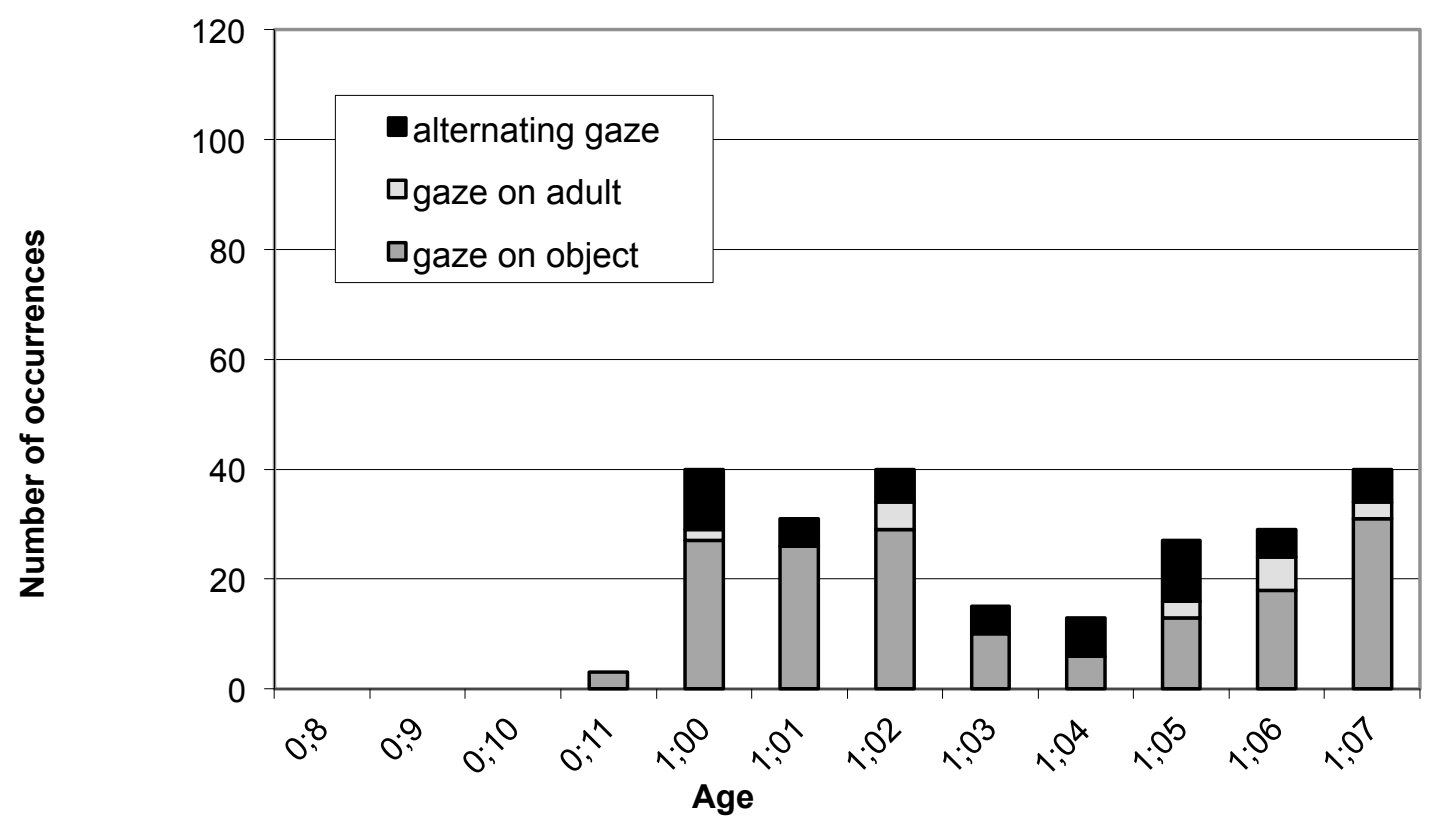

Figure 3. Number of occurrences of gaze on object, gaze on adult and alternating gaze during Madeleine's pointing events 
Morgenstern, A. (2014). Shared attention, gaze and pointing gestures I hearing and deaf children in Inbal Arnon, Marisa Casillas, Chigusa Kurumada \& Bruno Estigarribia (Eds.), Language in Interaction. Studies in honor of Eve V. Clark. Amsterdam/Philadelphia: John Benjamins.139-156.

Gaze and visual checking show interestings features for Charlotte (figure 2), but not as much for Madeleine (figure 3). Charlotte seems to have greater control over her use of gaze and to do more visual checking on adult (light grey and black). The overall proportion of gazes is shown in table 2

Table 2. Number of gaze on object, gaze on adult and alternating gaze in Madeleine and Charlotte's pointing events

\begin{tabular}{|l|l|l|l|l|}
\hline & Gaze on object & Gaze on adult & Alternating gaze & Total \\
\hline Charlotte & $252(39 \%)$ & $290(44 \%)$ & $110(17 \%)$ & 643 \\
\hline Madeleine & $175(73 \%)$ & $19(8 \%)$ & $44(17 \%)$ & 238 \\
\hline
\end{tabular}

The proportion of gazes on the adult in Madeleine's pointing events is quite significantly lower than in Charlotte's pointing events $\left(\chi^{2}(1)=57.6, p<0.00001\right)$ and conversely the proportion of gazes on the object in Madeleine's pointing events is significantly higher $\left(\chi^{2}(1)=25.3, p<0.00001\right)$. Alternating gazes are used in the same proportions by both girls $\left(\chi^{2}(1)=0.09, p=0.76\right)$. Madeleine, on the other hand, can use another modality to catch the adult's attention: the auditory modality.

\subsection{Use of vocal and verbal productions during pointing events in Madeleine's data}

When we counted the number of pointing gestures that were produced simultaneously to vocal productions, we found very high frequencies as shown in figure 4 (in dark grey). 
Morgenstern, A. (2014). Shared attention, gaze and pointing gestures I hearing and deaf children in Inbal Arnon, Marisa Casillas, Chigusa Kurumada \& Bruno Estigarribia (Eds.), Language in Interaction. Studies in honor of Eve V. Clark. Amsterdam/Philadelphia: John Benjamins.139-156.

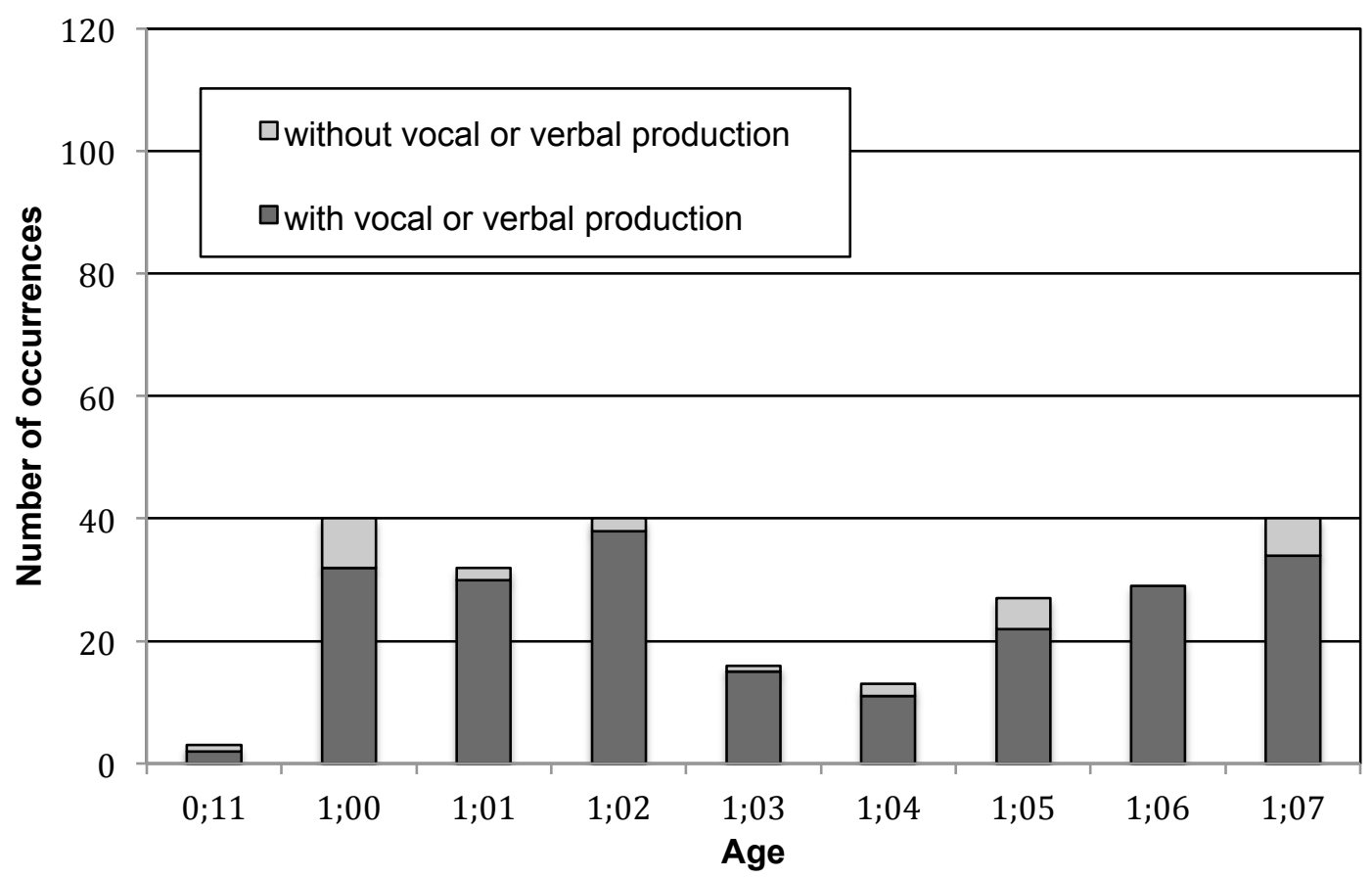

Figure 4. Number of pointing events with and without vocal productions in Madeleine's data

It is quite clear that silent points are rare in Madeleine's data, they represent $13 \%$ of all pointing events: in fact they often occur as a reaction to an adult's question to localize an object. Vocalizing while pointing seems to be the rule for Madeleine and it may well serve the aim of getting and sharing attention as much as adding supplementary or complementary proto-words or words to the pointing gesture. For example Madeleine at $1 ; 05$ says [sisis] as she points to the CD player (meaning musique/music) or says [vave] (laver/wash) as she points at a stain on her doll's head. The association between pointing and vocalization or verbalization is found $100 \%$ of the time in experimental situations according to Franco and Butterworth (1996). Guidetti (2003) compared pointing with other types of gesture, like "bye bye" and observed that 
Morgenstern, A. (2014). Shared attention, gaze and pointing gestures I hearing and deaf children in Inbal Arnon, Marisa Casillas, Chigusa Kurumada \& Bruno Estigarribia (Eds.), Language in Interaction. Studies in honor of Eve V. Clark. Amsterdam/Philadelphia: John Benjamins.139-156.

more of these types of gesture are produced alone whereas pointing gestures are massively used with vocal or verbal productions.

We also observed that as she gets older, Madeleine uses fewer pointing gestures when she produces deictics, as shown in figure 5 .

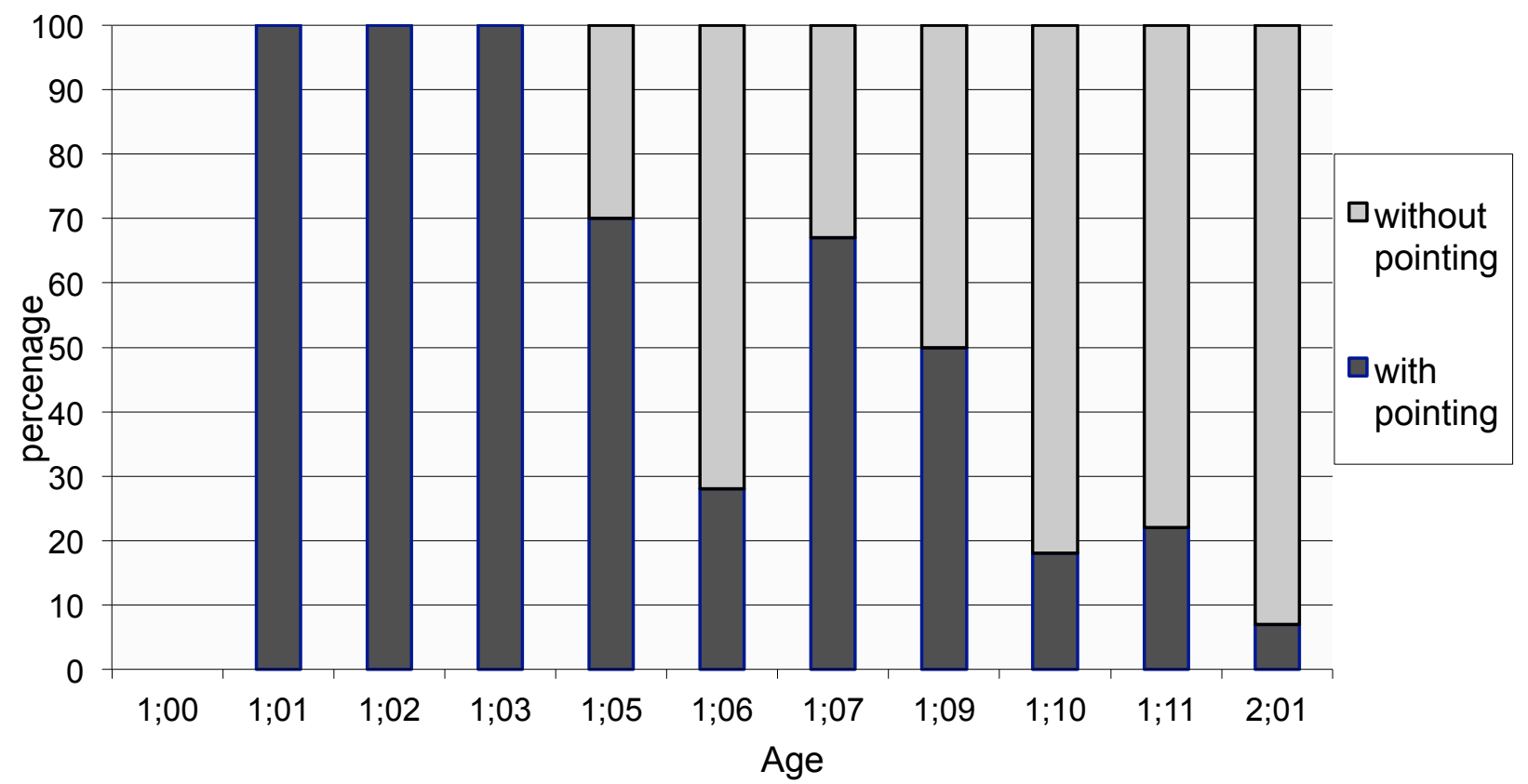

Figure 5. Number of deictics used with and without pointing gestures

in Madeleine's data

Apart from locating an object in space in a very precise way, which she still does at four years old (she points at a stain and says "je me suis tâchée là" /I stained myself here), Madeleine progressively replaces referential pointing gestures by deictics ${ }^{10}$. She avoids redundant information but also talks more often about absent objects or events

\footnotetext{
${ }^{10}$ However, Madeleine continues to use co-verbal pointing gestures with a whole range of diversified functions as her communicative skills become more and more complex. She demonstrates excellent mastery of the location, the orientation, the motion of her pointing gestures, which enables her to mark subtle differentiation of their functions. She uses pointing for example to refer to time-spans or to attenuate, to suspend the predication she is making in speech.
} 
Morgenstern, A. (2014). Shared attention, gaze and pointing gestures I hearing and deaf children in Inbal Arnon, Marisa Casillas, Chigusa Kurumada \& Bruno Estigarribia (Eds.), Language in Interaction. Studies in honor of Eve V. Clark. Amsterdam/Philadelphia: John Benjamins.139-156.

she can't directly point at. In French Sign Language, points are grammaticalized into deictics (personal and demonstratives pronouns in particular) and those grammatical markers are used just as frequently as their equivalent in French.

\section{Conclusions}

We found that in the hearing child's data, gaze on the object could be considered as being non marked and gaze on the adult as being marked. The hearing child only uses the latter when in the situation pointing plus vocal production are not enough to attract the adult's attention. Our hypothesis is that in oral languages, at least in French, vocal and verbal productions are the dominant modality to attract attention. Vocal productions are thus used to ATTRACT attention, pointing gestures enable the child to DIRECT attention, and gaze is only used to CHECK that the attention is there when there is a clear doubt or if the target is extremely important for the child. In the case of the deaf child in a signing environment, she will use a combination of gaze + pointing in order to ATTRACT, DIRECT and CHECK the adult's attention. Gaze is therefore used much more frequently and more expertly both to check and direct the adult's attention. Deaf signing children get precocious specific training in the use of gaze. In their daily communication, whenever they ask a question for example, deaf children must keep their gaze on their interlocutor if they want to see the reply. It is not the case of the hearing child who can go back to her activity and still catch the language addressed (or not addressed) to her. 
Morgenstern, A. (2014). Shared attention, gaze and pointing gestures I hearing and deaf children in Inbal Arnon, Marisa Casillas, Chigusa Kurumada \& Bruno Estigarribia (Eds.), Language in Interaction. Studies in honor of Eve V. Clark. Amsterdam/Philadelphia: John Benjamins.139-156.

Because of its visual nature, in sign language acquisition, gaze and pointing are clearly privileged. At two years old, Charlotte has extensive expertise in using gaze with her adult interlocutors. She is fully aware of the adults' attention and goes all the way near them if she clearly wants to communicate with them, whereas Madeleine can also increase the intensity of her voice to attract adults' attention. Charlotte even sometimes lifts her arms in order to reach the adults' visual field or bends to sign for her dolls as adults do with her. She also uses a much greater number of points than Madeleine who is progressively going to replace certain pointing gestures by words (deictics, nouns, predicates).

Monitoring and checking are basic ingredients of communicative acts. Before they monitor, check and repair their speech (Clark 1982), children learn to monitor and check adults' attention. This is already in place at a very early age thanks to pointing and gaze, which are two of the main instruments adults and children use to manage the attention of the interlocutor. Hearing children use vocal productions to complement pointing and gaze and therefore seem to rely on them less than deaf children.

The comparison between deaf and hearing children gives us some insights into the nature/nurture debate. Deaf signing children do not have the same biological foundations as hearing children. But they develop an expertise at using the visual modality, which hearing children also have the capacity to develop, but do not need to depend solely on, since they also resort to the auditory modality. Unfortunately, not all deaf children are surrounded by expert users of the visual modality. A lot do not benefit from the necessary model and scaffolding early enough to learn through the use of gaze and pointing to share attention and make links between objects, persons, events, affects 
Morgenstern, A. (2014). Shared attention, gaze and pointing gestures I hearing and deaf children in Inbal Arnon, Marisa Casillas, Chigusa Kurumada \& Bruno Estigarribia (Eds.), Language in Interaction. Studies in honor of Eve V. Clark. Amsterdam/Philadelphia: John Benjamins.139-156.

and language. But those who do benefit from it then have solid bases to become expert signers.

Despite great individual differences, and many possible paths, deaf and hearing children alike use all their capacities and all the input at their disposal, to master the greatest of social arts - language.

\section{References}

Baldwin, D. (1993). Infants' ability to consult the speaker for clues to word reference. Journal of Child Language, 20, 395-419.

Bates, E, Camaioni L. \& Volterra, V. (1975). The acquisition of performatives prior to speech. Merrill-Palmer Quaterly 21, 205-226.

Bellugi, U. and Klima, E.S. (1982). The acquisition of three morphological systems in American Sign Language. Papers and Reports on Child Language Development 21, 135.

Brazelton, T.B., Koslowski, B. \& Main, M. (1974). The origins of reciprocity; The early mother-infant interaction. In The effect of the infant on its caregiver, M. Lewis \& L. Rosenblum (Eds.), 49-76. Wiley.

Bruner, J., S. (1975). From communication to language: a psychological perspective. Cognition 3, 255-287.

Bruner, J. (1983). Child's Talk: learning to use language. New-York: Norton.

Butterworth G. \& Itakura, S. (2000). How the eyes, head and hand serve definite reference. British Journal of Developmental Psychology. Volume 18, Issue 1: 25-50. 
Morgenstern, A. (2014). Shared attention, gaze and pointing gestures I hearing and deaf children in Inbal Arnon, Marisa Casillas, Chigusa Kurumada \& Bruno Estigarribia (Eds.), Language in Interaction. Studies in honor of Eve V. Clark. Amsterdam/Philadelphia: John Benjamins.139-156.

Clark, E. V. (1978). From gesture to word: On the natural history of deixis in language acquisition. In J. S. Bruner \& A. Garton (Eds.), Human growth and development: Wolfson College lectures 1976. Oxford: Oxford University Press, pp. 85 - 120.

Clark, E. V. (1982). Language change during language acquisition. In M. E. Lamb \& A. L. Brown (Eds.), Advances in developmental psychology (Vol. 2). Hillsdale, NJ: Lawrence Erlbaum Associates, pp. 173-197.

Cole, M. \& Cole, S. A. (1996). The Development of Children. NY: Scientific American Books. Cormier, K (2010) Pronouns and pointing: Where do sign languages fit in? In:

(Proceedings) Between you and me: Local pronouns across modalities. : Radboud University, Nijmegen.

Courtin, C. (2000). The Impact of Sign Language on the Cognitive Development of Deaf Children. The Case of Theories of Mind. J. Deaf Stud. Deaf Educ. 5 (3): 266-276.

Cuxac, C. (2000). La langue des signes française (LSF). Les voies de l'iconicité. Ophrys, Paris.

Darwin, C. (1877). A biographical sketch of an infant. Mind 2, 285-294.

Deák, G.O., \& Triesch, J. (2006). Origins of shared attention in human infants. In K. Fujita \& S. Itakura (Eds.), Diversity of Cognition. University of Kyoto Press, pp. 331-363.

Deák, G. , Jasso, H. , Krasno, A. and Triesch, J. (2006) Watch the Hands: Infants Learn Gaze-Following From Parents' Pointing and Manual Action, Paper presented at the annual meeting of the XVth Biennial International Conference on Infant Studies, Westin Miyako, Kyoto, Japan. 2012-06-25.

Estigarribia, B. \& Clark, E. V. (2007). Getting and maintaining attention in talk to young children. Journal of Child Language. 34, 799-814. 
Morgenstern, A. (2014). Shared attention, gaze and pointing gestures I hearing and deaf children in Inbal Arnon, Marisa Casillas, Chigusa Kurumada \& Bruno Estigarribia (Eds.), Language in Interaction. Studies in honor of Eve V. Clark. Amsterdam/Philadelphia: John Benjamins.139-156.

Evans, N \& Levinson, S., C. (2009). The myth of language universals: Language diversity and its importance for cognitive science. Behavioral and Brain Sciences, 32, 429-492.

Filipi, A. (2009). Toddler and Parent Interaction: The organization of gaze, pointing and vocalization. Amsterdam: John Benjamins.

Flom, R. Deak, G., Phill, C.G. \& Pick, A.D. (2003). Nine-month-olds' shared visual attention as a function of gesture and object location. Infant Behavior and Development, 27, 181-194.

Franco F., and Butterworth, G. (1996). Pointing and social awareness: declaring and requesting in the second year. Journal of Child Language. 23, pp 307-336

Guidetti, M. (2003). Pragmatique et psychologie du développement : comment communiquent les jeunes enfants. Paris: Belin.

Hoiting, N. \& Slobin, D. I. (2007). From gestures to signs in the acquisition of sign language. In S. DK Duncan, J. Cassell, \& E. T. Levy (Eds.), Gesture and the dynamic dimension of language: Essays in honor of David McNeill. Pp. 51-65. Amsterdam/Philadelphia: John Benjamins.

Hoiting, N. (2009). The myth of simplicity. Sign language acquisition by Dutch deaf toddlers. Doctoral Dissertation. University of Groningen.

Iverson, J. \& Goldin-Meadow, S. (2005). Gesture paves the way for language development. Psychological Science 16 (5), 367-371.

Kelly, B.F. (2011). A new look at redundancy in children's gesture and word combinations in Inbal Arnon and Eve V. Clark (Eds.), Experience, Variation and Generalization: Learning a first language. Benjamains - John Benjamins Publishing company. 73-90.

Kendon, A. (2004). Gesture: Visible Action as Utterance. Cambridge: Cambridge UP. 
Morgenstern, A. (2014). Shared attention, gaze and pointing gestures I hearing and deaf children in Inbal Arnon, Marisa Casillas, Chigusa Kurumada \& Bruno Estigarribia (Eds.), Language in Interaction. Studies in honor of Eve V. Clark. Amsterdam/Philadelphia: John Benjamins.139-156.

Kita, S. (Ed.). (2003). Pointing: Where Language, Culture and Cognition Meet. Mahwah, NJ: Lawrence Erlbaum Associates.

Leroy, M. ; Mathiot, E. ; Morgenstern, Aliyah (2009) Pointing gestures and demonstrative words : Deixis between the ages of one and three. Studies in Language and Cognition. Cambridge Scholars Publishing. Editors: Jordan Zlatev, Marlene Johansson Falck, Carita Lundmark and Mats Andrén. P. 386-404.

Limousin, F. (2011). Acquisition de la référence personnelle en LSF : Analyse longitudinale des pointages, des formes nulles et des noms signés chez une enfant sourde de parents sourds. Unpublished PhD manuscript. Université Paris 8.

Lutchmaya, S.; Baron-Cohen, S.; Raggatt P., (2002). Foetal testosterone and vocabulary size in 18- and 24-month-old infants. Infant Behavior and Development 24(4):418-424. Masataka, N. (1996). Perception of motherese in a signed language by 6-month-old deaf infants. Developmental Psychology, 32, 874-879.

Mayberry, R. I. \& Squires, B. (2006). Sign Language: Acquisition. In E. Lieven (Ed.), Language Acquisition, Vol. 11, Encyclopedia of Language and Linguistics. 2nd. Edition. Oxford: Elsevier.

McNeill, D. (1992). Hand and mind: What gestures reveal about thought. Chicago: University of Chicago Press.

Meristo, M., Morgan, G., Geraci, A., Iozzi, L., Hjelmquist, E., Surian, L., \& Siegal, M. (in press). Belief attribution in deaf and hearing infants. Developmental Science.

Morgenstern, A.. (1997). L'enfant sourd énonciateur-signeur: l'auto-désignation chez l'enfant en Langue des Signes Française. LIDIL 15: 119-140.

Morgenstern, A. \& Sekali, M. (2009). What can child language tell us about prepositions? A contrastive corpus-based study of cognitive and social-pragmatic factors. Studies 
Morgenstern, A. (2014). Shared attention, gaze and pointing gestures I hearing and deaf children in Inbal Arnon, Marisa Casillas, Chigusa Kurumada \& Bruno Estigarribia (Eds.), Language in Interaction. Studies in honor of Eve V. Clark. Amsterdam/Philadelphia: John Benjamins.139-156.

in Language and Cognition, Cambridge Scholars Publishing. Editors: Jordan Zlatev, Marlene Johansson Falck, Carita Lundmark and Mats Andrén. P. 261-275.

Morgenstern, A. (2009). L'enfant dans la langue. Presses de la Sorbonne Nouvelle.

Morgenstern, A., Caet, S., Collombel-Leroy,M., Limousin, F. \& Blondel, M. (2010). From gesture to sign and from gesture to word: Pointing in deaf and hearing children. Gesture 10.172-202.

Morgenstern, A \& Parisse, C. (2012). The Paris Corpus. Journal of French Language Studies 22(1), 7-12, Cambridge University Press.

Petitto, L., A. (1986). From gesture to symbol: the relationship between form and meaning in the acquisition of personal pronouns in American Sign Language. Bloomington, IN: Indiana University Linguistics.

Pizzutto, E. \& Capobianco, M. (2005). The link and differences between deixis and symbols in children's early gestural-vocal systems. Gesture, 5 (1), 175-195.

Schick, B. (2003). The development of ASL and Manually-Coded English systems. In M. Marschark \& P. E. Spencer (Eds.), Oxford Handbook of deaf studies, language, and education. New York: Oxford University Press.

Sekali, M. (2012). The emergence of complex sentences in a French child's language from 0;10 to 4;01: causal adverbial clauses and the concertina effect. In M. Sekali (ed) First language acquisition of French grammar (from 10 months to 4 years old), Special issue of Journal of French Language Studies, 22-1, Cambridge: Cambridge University Press, pp. 115-141.

Stern, W. (1924). Psychology of early childhood, London, Unwin. (German edition 1914). Tomasello, M. (1999). The cultural origins of Human Cognition. Harvard University Press. 
Morgenstern, A. (2014). Shared attention, gaze and pointing gestures I hearing and deaf children in Inbal Arnon, Marisa Casillas, Chigusa Kurumada \& Bruno Estigarribia (Eds.), Language in Interaction. Studies in honor of Eve V. Clark. Amsterdam/Philadelphia: John Benjamins.139-156.

Tomasello, M. (2003). Constructing a language: a usage-based theory of language acquisition. Cambridge, MA : Harvard University Press.

Tomasello, M., Carpenter, M., \& Liszkowski, U. (2007). A new look at infant pointing. Child Development, 78, 705-722.

You, Y., Deak, G. 0., Jasso, H. and Teuscher, D. (2005). Emergence of shared attention from 3 to 11 months of age in naturalistic infant-parent interactions. Biennal meeting of the Society for research in child development, Atlanta, GA.

Werner, H. \& Kaplan, B.. (1963). Symbol formation. Hillsdale, NJ: Erlbaum. 